\title{
O altersense do haicai
}

\author{
Haiku's altersense \\ Ana Fernandes \\ Pontifícia Universidade Católica do Rio de Janeiro, Rio de Janeiro, Rio de Janeiro, Brasil \\ João Queiroz \\ Universidade Federal de Juiz de Fora, Juiz de Fora, Minas Gerais, Brasil
}

$$
\diamond
$$

Resumo: O haicai tem sido alvo de uma enorme quantidade de análises. De Barthes a Leminski, de Haroldo de Campos a Octavio Paz, para mencionar apenas alguns dos mais conhecidos, as análises se concentram na forma justa e densamente estruturada do poema e na brevidade do acontecimento representado. Trata-se de uma ideia que já foi muito explorada, e da qual extraímos novas consequências. Em nossa descrição, baseada na faneroscopia de Charles S. Peirce, o haicai não é o signo de um acontecimento, mas do altersense do haijin, que é a "consciência de um presente diretamente outro, ou segundo" (CP 7.551) do poeta. De acordo com essa abordagem, o haicai é um signo, ao mesmo tempo icônico e indexical, que representa um “departamento da ação mental” (CP 7.539).

Palavras-chave: Haicai; Altersense; Faneroscopia; Peirce

\begin{abstract}
Haiku has been the target of a great quantity of analyzes. From Roland Barthes to Paulo Leminski, from Haroldo de Campos to Octavio Paz, the analyzes concentrate in the exact structure of the poem, on the brevity of the event, and on the phenomenology of the poet under the effect of this experience. Our purpose here is to make a phenomenological description of haiku, based on the faneroscopy and semiotics of C. S. Peirce. According to our approach, haiku is an iconic and indexical sign that represents an "department of mental action" (Peirce CP 7,539), altersense, which is the "consciousness of a directly present other, or second" (Peirce CP 7.551).
\end{abstract}

Keywords: Haiku; Altersense; Phaneroscopy; Semiotics; Peirce 


\section{Introdução}

Matsuo Bashô, conhecido como o mais importante mestre haijin ${ }^{2}$ do período Edo no Japão, transformou o haicai num exercício mental de síntese do instante poético - "Bashô: haikai é apenas o que está acontecendo aqui e agora" (LEMINSKI, 1983, p.22). A busca por esse instante, segundo Octavio Paz, está relacionado ao satori, termo utilizado na filosofia Zen que indica um estado que "é aqui e agora, um instante que é todos os instantes, momento de revelação em que o universo inteiro - e com ele a corrente de temporalidade que o sustenta - se desmorona" (PAZ, 1976, p. 160). Para Barthes (2007, p.99), "a brevidade do haicai [de Bashô e seus discípulos] não é formal; o haicai não é um pensamento rico reduzido a uma forma breve, mas um acontecimento breve que acha, de golpe, a forma justa". O gênero é frequentemente comparado à fotografia, "uma espécie de objetiva portátil, apta a captar a realidade circunstante e o mundo interior, e a convertê-los em matéria visível" (CAMPOS, 1972, p. 65).

De Barthes a Leminski, de Haroldo de Campos a Octavio Paz, para mencionar apenas alguns dos mais conhecidos, as análises se concentram na forma densamente estruturada do poema e na brevidade do acontecimento representado. Muitos autores se dedicaram à descrição da experiência associada ao instante perceptual decisivo do haijin que materializase no haicai. Este é o foco deste artigo. Introduzimos a faneroscopia de C.S.Peirce ${ }^{3}$ para detalhar a relação entre a experiência do haijin e o haicai. Esta ideia já foi introduzida por outros autores (SOUSA, 2007; LEMINSKI, 2012), mas extraímos dela consequências ainda não exploradas. Em nossa abordagem, o haicai não é o signo de um acontecimento, mas do altersense do haijin, que é a "consciência de um presente diretamente outro, ou segundo" (CP 7.551). Ele é um signo que referese ao seu objeto - altersense - através de processos que são, ao mesmo tempo, icônicos e indexicais. Sobre este aspecto, há, entre as abordagens mais conhecidas, e baseadas na teoria do signo de Peirce, uma negligência que tem produzido diversos equívocos. Para Leminski, por exemplo, o haicai é um ícone - "fotos e haicais são ícones: ícones são coisas" (LEMINSKI, 2011, p. 142). Fontanari (2011, p.34) está diante do noema barthesiano tipicamente indexical da fotografia - "isso foi" ou "isso existiu" -, quando sugere sua semelhança com o haicai.

\footnotetext{
$\overline{2}$ Haijin é o praticante do haicai (GUTILLA, 2009, p. 9).

3 A obra The collected papers of Charles S. Peirce (1866-1913) será citada como CP, seguida pelo número do volume e do parágrafo; The essential Peirce (1893-1913) e Writings of Charles S. Peirce (1839-1914) como $\mathrm{EP}$ e W, respectivamente, seguidas pelo número do volume e da página; e Annotated catalogue of the Papers of Charles S. Peirce como MS, seguida pelo número do manuscrito.
}

Tais abordagens baseiam-se na divisão Peirceana do signo (ícone, índice, símbolo), e descrevem a relação signo-objeto $(\mathrm{S}-\mathrm{O})^{4}$ da tríade signo-objeto-interpretante (S-O-I) (QUEIROZ, 2004, p.21). O problema é que esta divisão nada informa sobre a natureza de $\mathrm{S}$, que é a natureza semiótica do haicai, sobre a natureza de $\mathrm{O}$, que é seu objeto, ou sobre o efeito interpretativo (I) que resulta da relação entre S e O, um "aqui-e-agora faneroscópico" do qual ele é uma "objetiva portátil". Trata-se de uma divisão capaz de descrever a relação entre o haicai, que é um signo, e seu objeto, que é um acontecimento, nas versões mais conhecidas, ou um estado faneroscópico, em nossa argumentação.

\section{Fenomenologia ou faneroscopia}

A fenomenologia de C.S.Peirce, ou faneroscopia ${ }^{5}$, como ele preferiu chamá-la, é uma ciência "ocupada com os elementos formais do fâneron", o "total coletivo de tudo que está, de qualquer modo, ou em qualquer sentido, presente à mente, sem consideração sobre se corresponde a algo real ou não" (CP 1.284). Como "a mais básica (primal) de todas as ciências positivas" (CP 5.39), teoricamente baseada na "pura matemática" (CP 5.40), a tarefa da faneroscopia é prover um catálogo exaustivo dos elementos mentais (CP 1.292). Suas principais questões são (i) quais os "elementos indecomponíveis" do fâneron? (MS 292:71-75) e (ii) como eles estão relacionados?

\begin{abstract}
O que chamo de Faneroscopia é aquele estudo que, baseado na observação direta dos fânerons, e generalizando suas observações, indica suas diversas classes gerais; descreve as características de cada uma delas; mostra que, embora inextricavelmente misturadas, tal que não podem ser isoladas, ainda assim é manifesto que seus caracteres são distintos; então prova, além de qualquer questão, que uma lista curta forma as mais gerais categorias que existem nos fânerons; finalmente, prossegue com a difícil e laboriosa tarefa de enumerar as principais subdivisões destas categorias (CP 1.286).
\end{abstract}

O resultado é um catálogo dos "departamentos da ação mental" (CP 7.539) e da explicação destes departamentos, e suas relações, a partir da análise de

\footnotetext{
4 Ao isolar analiticamente a relação signo-objeto (S-O), pode-se apenas examinar a relação entre o haicai e aquilo que ele representa. Em outro trabalho devemos explorar a natureza semiótica do haicai, baseado nas classificações estendidas de Peirce (FARIAS; QUEIROZ, 2017). De acordo com esta divisão, o haicai comporta-se como um legisigno indexical dicente (ou remático). Ele é da natureza de um símbolo (e, como todo símbolo, ele "contém" índices e ícones), está para (stands for) um evento ou instante particular, e pode ser interpretado indexicalmente ou rematicamente.

5 Sobre a faneroscopia de Peirce, recomendamos: Savan (1952), Rosensohn (1974), Spiegelberg (1981).
} 
seus componentes fundamentais, que são as "formas das estruturas dos elementos" fundamentais do fâneron (MS 292) 6 . Para Peirce, tais "departamentos" são constituídos por três "componentes fundamentais", isto é, por três componentes cuja "forma da estrutura" não pode ser explicada através de qualquer outro componente.

Todos os elementos da experiência pertencem a três classes que, desde que são melhor definidas em termos de números, podem ser chamadas Categorias Cenopitagóricas. A experiência é composta de 1st, experiências monádicas, ou simples [...]; 2st, experiências diádicas, ou recorrências [...] experiência direta de uma oposição de pares de objetos; 3 st, experiências triádicas, ou compreensões [...] experiência direta que conecta outras possíveis experiências (CP 7,528).

Toda a variedade de estados que constituem a mente consciente pode ser dividida em três formas feeling, ou experiência monádica, sentido de alteridade, ou experiência diádica, e sentido de mediação, ou experiência triádica. De acordo com esta divisão, há três tipos fundamentais de experiência: (i) "o conteúdo momentâneamente presente da consciência" (CP 7.551), (ii) a experiência de um outro diretamente presente, e (iii) a experiência de síntese ou mediação (CP 1.378). Para Peirce (CP 7.551),

não existem outras formas de consciência exceto as três mencionadas: Feeling, Sentido de alteridade (Altersense), e Sentido de mediação (Medisense). Eles formam um tipo de sistema. Feeling é o conteúdo momentaneamente presente da consciência em sua simplicidade pristina, à parte qualquer outra coisa. É a consciência em seu primeiro estado, e poderia ser chamada primesense. Sentido de alteridade (altersense) é a consciência de um presente diretamente outro, ou segundo. [...] Sentido de mediação é a consciência de uma terceiridade, ou meio entre um Sentido de primeiro e um Sentido de Alteridade. [...] É a consciência de um processo de 'trazer para mente'.

A primeiridade está associada à experiência de vagueza e indeterminação.

\footnotetext{
6 A questão sobre o que são os "elementos indecomponíveis do fâneron" (MS 292) pode ser comparado ao problema matemático das quatro cores (W 4: XIVI): "qual o número mínimo de cores suficientes para colorir os países mostrados por um mapa de modo que nenhum país adjacente seja colorido com a mesma cor? Tem sido sugerido, mas não provado, que a resposta a este problema é quatro." Esta metáfora epistêmica também tem estreita correspondência com descobertas da química (TURSMAN, 1987, p. 28), especialmente da tabela periódica (CP 5.469), e do "poder de combinação de um átomo ou radical" (PICARDI, 1990), onde a questão é formulada em termos "faneroquímicos" - classes de conexões, descritas como valências, aparecem indissoluvelmente combinadas e misturadas no fâneron, que é "analiticamente quebrado" (MARTY, 1982, p. 169) em seus elementos constitutivos.
}

Imagine uma consciência em que não há qualquer comparação, nenhuma relação, nenhuma multiplicidade reconhecida, nenhuma mudança, nenhuma imaginação de qualquer modificação do que está positivamente lá, nenhuma reflexão - nada além de uma simples característica positiva. Tal consciência poderia ser apenas um odor [...]. A primeira categoria é uma qualidade de feeling (EP 2: 150);

A secundidade está relacionada às ideias de reação, esforço, resistência, existência; está envolvida nas ocorrências, na negação, e na compulsão. "Segundo" é aquilo que requer "outro". A causalidade mecânica, de efeito eficiente, sem propósito, ou planejamento; o evento particular, não conformado a uma sequência ou processo, não submetido a qualquer tendência; a compulsão para ação imediata, sem objetivo previsto ou suposto "secundidade é o modo de ser daquilo que é tal como é, com respeito a um segundo mas sem observar qualquer terceiro" (CP 8.328); "a idéia de outro, de não, torna-se o pivô do pensamento" (CP 1.324). Esta categoria está associada à atualização, ao acontecimento, a realização de algo, "esta entidade, aqui, neste momento"; o "aqui-e-agora", singular e particular. Se a primeiridade é independência e autonomia, a secundidade é tipificada pela reação com outra coisa.

Mas para Peirce, é "impossível resolver tudo em nossos pensamentos por meio destes dois elementos" (CP 1.343), primeiridade e secundidade. Se a secundidade é caracterizada pela reação, a terceiridade é a categoria da inteligência. A terceiridade pode ser observada na persistência regular, e temporal. Como a "cognição depende da conexão entre coisas" (HAUSMAN, 1993: 12), as relações de mediação são aquelas que exemplificam com maior precisão esta categoria "algumas das idéias de terceiridade proeminentes [...] são generalidade, infinidade, continuidade, difusão, crescimento e inteligência" (CP 1.340). A semiose é um fenômeno exemplar - signo, objeto, interpretante estão relacionados em um tipo de interdependência que não pode ser decomposto em relações mais simples.

\section{Lógica do signo e classes fundamentais}

Qual "a natureza essencial e variedade fundamental de todas as possíveis semioses"? (CP 5.488) Para Peirce, a semiose consiste em uma relação entre três termos irredutivelmente conectados (signo-objeto-interpretante), que são seus elementos constitutivos (CP 5.484; MS 318: 81; EP 2: 171). Mas ele também define um signo como um meio para a comunicação de uma "forma", ou para transferência de um hábito incorporado no objeto para um intérprete, de tal modo a restringir seu comportamento (QUEIROZ; EL-HANI, 2006). A 
"forma" está incorporada no objeto (EP 2.544, n. 22) como uma "regra de ação" (CP 5.397; CP 2.643), uma "disposição" (CP 5.495; CP 2.170), um "potencial real" (EP 2.388) ou, simplesmente, a "permanência de alguma relação" (CP 1.415).

[...] um Signo pode ser definido como um Meio para a comunicação de uma Forma. Como um meio, o Signo está essencialmente em uma relação triádica, com seu Objeto que o determina, e com seu Interpretante que ele determina. [...] Aquilo que é comunicado do Objeto através do Signo para o Interpretante é uma Forma; significa dizer, não é nada como um existente, mas é um poder, o fato de que alguma coisa aconteceria sob certas condições (EP 2: 544, n. 22).

No contexto da "mais fundamental divisão dos signos" (CP 2.275), ícones, índices e símbolos correspondem a relações de similaridade, contiguidade e lei entre $\mathrm{S}$ e $\mathrm{O}$, na tríade S-O-I. O ícone é usualmente definido como um signo que se baseia em relações de similaridade (CP 2.276), ou de analogia (CP 1.369), que pode prescindir de qualquer correlação espaço-temporal que possa ter com um objeto existente (CP 5.73; CP 2.247). Ele é logicamente dependente de suas propriedades - "eu defino um ícone como um signo que é determinado por seu objeto dinâmico em virtude de sua própria natureza interna" (CP 8.335). Em outras palavras, são as qualidades que pertencem ao signo que determinam sua interpretação de tal forma que qualquer objeto que tem qualidades similares pode ser interpretado como seu objeto. O signo icônico "serve como um signo simplesmente por exibir a qualidade de que se serve para significar" (NEM 4: 242). Os ícones estão presentes no reconhecimento de padrões e em relações analógicas. Nos processos icônicos, o que é comunicado ao intérprete através do signo é uma qualidade que o signo compartilha com seu objeto. Tratase do único tipo de signo envolvendo uma apresentação direta de qualidades que pertencem a seu objeto. Em termos operacionais, ele pode ser definido como um signo que, ao ser observado ou manipulado, "revela" um, ou muitos, aspectos de seu objeto.

Em contraste com o ícone, se $\mathrm{S}$ é signo de $\mathrm{O}$ em razão de uma relação diádica (2-ádica) com ele, então ele é um índice. Neste caso, $\mathrm{S}$ e $\mathrm{O}$ estão relacionados através de uma "conexão física direta" (CP 1.372). S é realmente determinado por $\mathrm{O}$, e ambos devem coexistir como eventos - "um índice é um signo que se refere ao objeto que denota em virtude de ser realmente afetado pelo objeto" (CP 2.248). A noção de co-variação espaçotemporal é a propriedade mais característica dos processos indexicais. Os exemplos incluem de um "pronome demonstrativo ou relativo", que "força a atenção para um objeto particular, sem descrevê-lo" (CP 1.369), a sintomas físicos de doenças, fotografias e termômetros (CP 2.265). O que é comunicado ao intérprete é uma correlação espaço-temporal entre dois eventos. Em um incêndio, por exemplo, a fumaça é signo de fogo. A forma comunicada do objeto para o interpretante através do signo é uma correlação existente entre fogo e fumaça. Este tipo de índice foi classificado por Peirce como "reagente" (CP 8.368). Dois eventos singulares e existentes têm suas naturezas coincidentemente modificadas. Em termos sumários, um signo indexical comunica um hábito incorporado no objeto para o interpretante como um resultado de uma conexão direta entre signo e objeto.

Já o símbolo é um signo que está relacionado ao seu objeto em virtude de uma lei; ele comunica uma lei para seu intérprete. Símbolos são capazes de representar "coisas" que não precisam existir de fato, ou que existem mas não estão perceptualmente manifestas, que jamais existiram, ou, ainda, em termos antroposemióticos, que não podem sequer ser intuitivamente concebidas (objetos das lógicas não-clássicas, criaturas imaginárias, etc). Uma importante propriedade dos símbolos é que restrições impostas à presença espaço-temporal do objeto representado pelo índice, que ele conecta coincidentemente, não tem lugar em processos simbólicos. O índice é um signo causalmente "ancorado" em correlações espaço-temporais, uma vez que depende de uma coincidência com o objeto que representa. Segundo Peirce, em um símbolo, a relação entre $\mathrm{S}$ e $\mathrm{O}$ (signo e objeto) é logicamente dependente do terceiro termo da relação, o interpretante (I) - "o símbolo está conectado com o objeto em virtude da ideia de uma mente que usa o símbolo, sem a qual tal conexão não existiria" (CP 2.299).

A partir daqui, e de volta ao fenômeno que nos interessa, podemos perguntar: qual a natureza da relação entre o haicai e o objeto que ele representa? Qual a natureza do objeto que ele representa? Para abordar estas questões faremos uma breve introdução ao gênero poético inaugurado por Bashô.

\section{Haicai - breve contexto histórico}

Eis a forma

Do vento do outono:

O capinzal

(Kigin)

Poema de origem japonesa (LEMINSKI, 1983; PAZ, 1976), o haicai descende de um processo de adaptação cultural milenar que resultou numa vasta produção poética criativa (FRANCHETTI, 2008; CAMPOS, 1972). Inicialmente chamado de waka (wa = expressão designativa de Japão e $k a=$ poema, canto), aquilo que vem a se tornar o haicai é registrado pela primeira vez 
numa compilação de cerca de quatro mil e quinhentos poemas, distribuídos em vinte volumes, no primeiro e mais importante documento-livro poético da história do país, o Man'yôshu, ou Antologia de dez mil folhas, elaborado entre os séculos VII e VIII. A forma poética predominante no Man'yôshu é o tanka, que significa, numa tradução livre, "poesia curta" (SOUSA, 2007, p.25). O tanka é uma estrutura tradicional da poesia japonesa, um "composto de 5-7-5-7-7 sílabas. Também chamado misohitomoji, ou 'poema de 31 sílabas', o tanka divide-se em duas unidades ou estrofes" (GUTTILLA, 2009 , p. 7). A primeira unidade ou estrofe da estrutura, é formada por 5-7-5 sílabas distribuídas entre os versos, chamada kami no $\mathrm{ku}$, a segunda unidade ou estrofe da estrutura, contém 7-7 sílabas distribuídas entre os versos, e é conhecida como shimo no ku. De acordo com Paz (1976, p. 157), esta estrutura possibilitou, desde o seu surgimento, que dois poetas participassem da criação conjunta de um poema: "um escrevia as três primeiras linhas e o outro as duas últimas".

Essa prática, um desenvolvimento do que encontramos no Man'yôshu, deu origem a séries inteiras, compilações "ligadas tenuemente pelo tema da estação? Estas séries de poemas em cadeia são conhecidas como renga. O gênero ligeiro, cômico ou epigramático, chamouse renga haikai e o poema inicial hokku" (PAZ, 1976, p. 157). É no momento de separação da estrofe renga haikai, do restante da estrutura, hokku, que o haicai inicia sua trajetória como expressão poética independente. Para Paz (1976, p. 158), "o poema solto, desprendido no renga hai-kai, começou a chamar-se haiku, palavra composta de hai-kai e hokku". O termo haikai, cujo significado é poema de dezessete sílabas (HIRASHIMA, 2007, p. 105), ou sua nomenclatura abrasileirada haicai, passa então a ser adotado pelos praticantes do gênero e, "tendo em vista o parentesco do metro japonês (5-7) com a redondilha (menor e maior)" (GUTTILLA, 2009, p. 12). Em fins do século XVIII, e princípio do século XIX, o haicai se consolida "como uma forma propriamente autônoma" (PAZ, 1976, p. 158).

\section{Haicai - estruturação dos versos}

As flores

Da beira da estrada -

O cavalo acaba de comê-las

(Bashô)

Matsuo Bashô, haijin conhecido como o maior mestre da sucinta forma de escrever poesia (HAKUTANI, 2009;

\footnotetext{
Tema da estação, em japonês kigô, é tudo que faz referência ao tema das estações do ano, presente em todo haicai japonês. No Japão existe um livro com as principais referências. Ex: folhas, chuva, neve, frio, rochedo.
}

KERKHAM, 2006) foi quem codificou e estabeleceu os cânones do haicai tradicional. Com mais de três mil discípulos, Bashô, segundo Leminski, "buscou uma síntese. E a obteve. Sob certos aspectos, seu haicai é a fina flor de tudo que de melhor o Extremo Oriente produziu: transcendentalismo hindu, realismo e materialismo chinês, simplicidade japonesa" (LEMINSKI, 1983, p. 28-29). Sua tradição ficou conhecida como Shomôn, ou Escola de Bashô. O poeta, que viveu em peregrinação pelo Japão, buscou "revelar a beleza existente nas coisas modestas, humildes, imperfeitas, transitórias e não convencionais" (GUTTILLA, 2009, p. 8). Apropriandose da linguagem coloquial e desimpedida do haicai, Bashô pretendeu alcançar o que os antigos chamavam de instante poético. Para Sousa (2007, p.33), "antes de Bashô, o haicai era poesia cômica, epigrama, jogo de palavras. Ele transformou seu sentido, através da busca do instante poético. Dessa forma, sua poesia é um exercício espiritual". Em busca de autoconhecimento, ele eleva o haicai à condição do que é chamado no Japão de kadô, ou "caminho da poesia" - "crença na interdependência de todas as coisas da natureza, as grandes e as pequenas" (GUTTILLA, 2009, p. 8). Leminski, relatando um diálogo entre Bashô e o monge Bucchô, define o haicai como o instante capturado por escrito, o momento em três versos sucintos: "Bashô - Haikai é apenas o que está acontecendo aqui e agora. Então Bucchô compreendeu - Santa pessoa, esse Matsuo Bashô" (LEMINSKI, 1983, p. 22).

O haicai de Bashô é concebido com o máximo de concisão e simplicidade. Em termos métricos, como mencionamos, trata-se de "um poema de dezessete sílabas, com três versos; o primeiro e o terceiro, com cinco sílabas, o do meio com sete" (HAKUTANI, 2009 , p. 1). Do ponto de vista semântico, de forma não rigorosamente normativa, observa-se no primeiro verso a "circunstância eterna, absoluta, cósmica, não humana, normalmente, uma alusão à estação do ano, presente em todo haicai" (LEMINSKI, 1983, p.44); no segundo verso, "a ocorrência do evento, o acaso da acontecência, a mudança, a variante, o acidente casual" (LEMINSKI, 1983, p. 45); no terceiro, "o resultado da interação entre a ordem imutável do cosmos e o evento" (LEMINSKI, 1983, p. 45).

Segundo Campos (1972, p.57), o haicai relaciona dois elementos básicos dispersos entre os três versos, "um de permanência, a condição geral, como por exemplo a primavera, o fim do outono, o rochedo, etc., outro de transformação, a percepção momentânea". Os dois elementos básicos, de que trata Campos, são também destacados por Paz, quando este afirma que ele é dividido "em duas partes" (PAZ, 1976, p. 163). Para Paz, a primeira parte apresenta a condição geral, "descritiva e quase enunciativa” do poema (PAZ, 1976, p. 163), 
enquanto a segunda parte apresenta a condição inesperada, relampagueante, dotada de um elemento ativo. Assim, "a percepção poética do haicai surge do choque entre ambas condições" (PAZ, 1976, p. 163). O poema é uma "iluminação poética" (SOUSA, 2007, p. 12), a recriação de um acontecimento corriqueiro, trivial.

Após a abertura do país para o ocidente, Shiki, no intuito de perpetuar a arte da poesia japonesa, funda em 1892 a Escola Nippon-ha. Entre as principais regras da Escola, nota-se a preocupação com o rigor estrutural:

O poema deveria ser breve, resumindo-se a dezessete fonemas, ou sílabas; conter a referência à estação do ano (ou kigô) e ao local de sua criação; ser rico em onomatopeias; e, por fim, explicar o kireji, partícula expletiva que pode introduzir uma pausa, denotar a dúvida ou emoção do poeta diante do acontecimento que inaugura o poema - tal como a interjeição “ah!” na sintaxe ocidental (GUTTILLA, 2009, p. 10).

Observemos um poema de Bashô, “o mais lembrado poema da literatura japonesa” (LEMINSKI, 1983, p. 20), em tradução de Leminski (1983, p.42):

$$
\begin{aligned}
& \text { velho tanque } \\
& \text { o sapo salta } \\
& \text { o som da água }
\end{aligned}
$$

No primeiro verso vemos a "circunstância eterna"; nada mais que o velho tanque ocupa a mente do poeta. $\mathrm{O}$ segundo verso indica a ocorrência do evento, a mudança ou o acidente, que é o salto do sapo, o acontecimento percebido como uma interrupção da "circunstância eterna". O terceiro verso é "o resultado da interação entre a ordem imutável do cosmos, presente no primeiro verso, e o evento, do segundo verso" (LEMINSKI, 1983, p.45-46), que é o som do salto da rã. Para Paz:

\begin{abstract}
Na primeira linha encontramos o elemento passivo: o velho tanque e seu silêncio. Na segunda, a surpresa do salto da rã que rompe a quietude. Do encontro desses dois elementos deve brotar a iluminação poética. E esta iluminação consiste em retornar ao silêncio do qual o poema partiu, só que agora carregado de significação. À maneira da água que se expande em círculos concêntricos, nossa consciência deve expandir-se em ondas sucessivas de associações (PAZ, 1976, p. 164).
\end{abstract}

A percepção da alteridade, direta, orienta a atenção consciente do presente cujo recorte não exibe qualquer desenvolvimento temporal. O haicai, na tradição de Bashô, resulta da percepção de uma ação reativa, de "esforço", cuja predominância da secundidade caracteriza a experiência do altersense, sob o efeito do salto da rã, de sua reação ao evento. O objeto não é o fato ou o evento, mas a consciência reativa, surpreendente, de um presente sob domínio direto do evento.

\section{Haicai - natureza semiótica e faneroscópica}

\author{
Avaliando \\ Três mil haiku - \\ Dois caquis \\ (Shiki)
}

Sobre a natureza do haicai, muitos autores tentaram caracterizar seus aspectos icônicos e indexicais (BARTHES, 2007; SOUSA, 2007; LEMINSKI, 1983; PAZ, 1976; CAMPOS, 1972). O haicai, como muitas análises e descrições sugerem (BARTHES, 2007, p. 113), atua de modo indexical, apontando diretamente para o seu objeto, o "acontecimento breve". O índice possui importantes características, entre as mais mencionadas - contiguidade física, direcionamento da atenção, dissimilitude de seu objeto. A primeira está relacionada a sua dinâmica causal, muitas vezes ligada a noção de "causalidade eficiente" - a fumaça é um índice do fogo; o fogo é "causa eficiente" da fumaça (CP 5.73). De acordo com a segunda característica, o índice direciona a atenção para um fato, uma entidade particular, sem desenvolvimento no tempo ou no espaço, como uma seta ou um dedo indicando uma coisa. Outra importante propriedade é que o índice não necessita, como é o caso do ícone, ter qualquer semelhança com o objeto representado, nem precisa de qualquer interação cognitiva para existir como um acontecimento semiótico. Além disso, o índice não caracteriza o objeto; ele apenas indica sua existência. Esta é a posição de Haroldo de Campos, para quem o haikai funciona como uma "objetiva portátil", com propriedades supostamente indexicais (CAMPOS, 1972, p. 65).

Mas em nossa descrição, o haicai comporta-se, ao mesmo tempo, como um índice e como um ícone - ele direciona a atenção (índice) para um "departamento mental", e extrai dele certas propriedades características (ícone). Seu objeto é o altersense do haijin. O altersense tem um efeito causal do qual depende o haicai. Em outros termos, o objeto do haicai precisa ser experimentado pelo haijin como altersense. Trata-se de um domínio faneroscópico, que é representado, pelo haicai, como ícone e como índice.

Indexicalmente, mencionamos (acima) uma propriedade que satisfaz certas condições que caracterizam o haicai - causalidade eficiente. Em nosso exemplo, a fumaça é índice do fogo e é eficientemente causada pelo fogo (CP 2.248). Muitos autores têm destacado esta propriedade do haicai. Para Motta e Fontanari, “o haicai é a expressão, 
se assim poderia dizer, do reverso do tempo; um aqui-e-agora de um outrora. $\mathrm{O}$ real deixa seu rastro sobre o papel sem, entretanto, permitir-se envolver por digressões, alegorizações, comentários, ou qualquer outro tipo de infusão lírica" (MOTTA, FONTANARI, 2014, p. 129). A este aspecto está relacionada outra propriedade indexical - o índice nada informa sobre seu objeto, apenas o indica. Sem qualquer "expansão retórica" (BARTHES, 2004, p. 78), o objeto do índice é o instante percebido como uma alteridade, a atenção consciente de um presente que afeta um "segundo". Trata-se de uma experiência diádica, uma experiência de esforço e de reação, sem generalização, e sem submissão a qualquer experiência temporal - "uma percepção súbita (iluminação) a partir de uma sensação concreta e imediata" (MOTTA, FONTANARI, 2014, p. 129). Shiki, em um trecho traduzido por Blyth, é claro sobre o "aqui-e-agora" do haicai, em um panorama mais amplo sobre a poesia japonesa:

Quando o visitante diz que ninguém conseguiu até agora explicar-lhe o sentido do poema, Shiki responde: "O sentido desse verso é só o que está dito nele; ele não tem outro sentido, nenhum sentido especial. No entanto, os professores vulgares de haikai falam como se houvesse aí um sentido esotérico tão profundo que as pessoas comuns não pudessem entendê-lo. Nesse caso, o que se faz é enganar as pessoas. (...) Para conhecer o valor real deste verso, é preciso conhecer a história do haikai; este verso significa apenas que o poeta ouviu, o som de uma rã saltando para dentro de um velho poço - nada deve ser acrescentado a isso. Se você acrescentar qualquer coisa, já não se trata da real natureza do verso. Clareza e simplicidade, sem ocultar nada, sem recobrir nada, sem pensamento, sem ostentação técnica - eis o que caracteriza esse verso. Nada mais (BLYTH, 1963, p.47-76).

Iconicamente, o haicai é um "análogo" e uma "revelação" de certas propriedades do altersense. É bem conhecida a definição do ícone como "análogo" de seu objeto. Ícones são signos que estão para seus objetos através de similaridade, sem consideração por qualquer conexão espaço-temporal que possam ter com objetos existentes. A qualidade representativa do ícone é aquilo que Peirce descreve como uma "pura primeiridade categórica", que é uma qualidade que ele possui em simesmo, independente de qualquer outra coisa. Um caráter interno, "que pertence a ele, em si mesmo, como um objeto sensível, e que ele possuiria de qualquer forma, havendo ou não um objeto na natureza a que ele se assemelhe, ainda que jamais tenha sido interpretado como um signo" (CP 4.447). Leminski (2011) interpreta assim esta propriedade - "Fotos e haicais são ícones: ícones são coisas, coisas não tem tradução. Um ícone só pode ser adequadamente comentado por um outro ícone: é o que a história da arte, o jogo vital das influências, citações, cópias, paródias, pastiches" (LEMINSKI, 2011, p. 142).

Mas o ícone também é operacionalmente definido por Peirce como um signo cuja manipulação permite, por observação direta de suas propriedades intrínsecas, a descoberta de alguma informação sobre seu objeto (HOOKWAY, 2002, p. 102; STJERNFELT, 2011; QUEIROZ, 2010). Esta definição representa uma destrivialização da noção do ícone como um análogo do objeto representado. O ícone não é somente o único tipo de signo envolvendo uma apresentação direta de qualidades que pertencem a seu objeto; ele é também o único signo através do qual, por sua observação direta, se pode descobrir algo sobre seu objeto. O haicai é, ao mesmo tempo, um análogo e uma forma de investigação do altersense - "o poeta não diz: isso é triste, mas faz, sim, com que o próprio objeto seja triste, sem necessidade de acentuá-lo" (PAZ, 1976, p. 162).

A forma sintética, extremamente breve - "a linguagem altamente concentrada e vigorosa" (CAMPOS, 1972, p. 55) - é um ícone do altersense. O ícone de um presente "de grande enxutez" (FRANCHETTI, 2008; CAMPOS, 1972), o retrato de um momento (KANEOYA, 2008). Para Coelho (2014), algumas das características que permitem classificar o haicai como ícone do altersense do haijin incluem:

o registro de cenas do cotidiano; o abandono do detalhe e a busca da síntese, do resumo; o trabalho a favor do "equilíbrio geométrico" e do "acabamento técnico", além da "surpresa". (...) Investigações à procura da concisão (do que é breve e exato), da economia, do registro imediato das cenas (COELHO, 2014, p. 130).

\section{Conclusão}

A secundidade faneroscópica é descrita por Peirce como altersense, que "é a consciência de um presente diretamente outro" (CP 7.551). O haicai é um signo deste estado, representação indexical e icônica do aquie-agora do haijin. O estado experimentado pelo poeta como altersense é, portanto, o objeto do haicai. Ele resulta de uma operação que pode ser descrita como uma coincidência "atenção-evento", capturada com "precisão e leveza" (CAMPOS, 1972). Em contraste com uma interpretação muito corrente, em nossa descrição o haicai não é signo de um acontecimento, mas da experiência de um acontecimento. Ele é tanto um índice quanto um ícone desta experiência. Como um ícone, ele é um análogo de certas propriedades observadas no altersense. Ele revela, do altersense, algumas de suas propriedades mais importantes: brevidade, leveza, instantaneidade, descontinuidade. Para Leminski (2012, p. 141) “a própria 
brevidade torna o haicai imune a toda tentativa de ênfase. É uma unidade de informação quase pura”. Como um índice, ele aponta para o altersense, direciona a atenção para este "departamento mental" do haijin.

\section{Referências}

ATÃ, Pedro; QUEIROZ, João. Icon and Abduction: Situatedness in Peircean Cognitive Semiotics. In: MAGNANI, Lorenzo. (Org.). Model-Based Reasoning in Science and Technology. New York: Springer, 2013. p. 301-313.

BARTHES, Roland. O Império dos Signos. São Paulo: Martins Fontes, 2007.

BARTHES, Roland. A Câmara Clara: Nota sobre Fotografia. Rio Janeiro: Nova Fronteira, 2004.

BERGMAN, Mats. Reflections on the Role of the Communicative Sign in Semeiotic. Transactions of the Charles $S$. Peirce Society: A Quarterly Journal in American Philosophy, v. XXXVI, n. 2, p. 225-254, 2000.

BLYTH, Reginald. A History of Haiku. Tokyo: Hokuseido Press, 1963. Vol. II.

CAMPOS, Haroldo. A Arte no Horizonte do Provável. São Paulo: Perspectiva, 1972.

COELHO, Eduardo. O haicai e sua adaptação no Brasil. In: CALCANHOTO, Adriana (Org.). Haicai do Brasil. Rio de Janeiro: Edições de Janeiro, 2014. p. 130-141.

DE TIENNE, Andre. Learning qua semiosis. Semiotics, Evolution, Energy, and Development, v. 3, p. 37-53, 2003.

FARIAS, Priscila; QUEIROZ, João. Visualizando Signos. São Paulo: Blucher, 2017.

FONTANARI, Rodrigo; MOTTA, Leda. A Tentação do Haikai e a Experiência Traumática da Fotografia em Roland Barthes. Aletria, v. 24, n. 2, p. 127-139, 2014.

FRANCHETTI, Paulo. O haicai no Brasil. Alea: Estudos Neolatinos, v. 10, n. 2, 2008.

FRANCHETTI, Paulo; DOI, Elza. Haikai: Antologia e História. São Paulo: Unicamp, 2014.

GOGA, Masuda. O Haicai no Brasil. Tradução: José Yamashiro. São Paulo: Oriento, 1988.

GUTTILlA, Rodolfo. Boa Companhia: Haicai. São Paulo: Companhia das Letras, 2009.

HAUSMAN, Carl. Charles Sanders Peirce's Evolutionary Philosophy. Cambridge: Cambridge University Press, 1993.

HAKUTANI, Yoshinobu. Haiku and Modernist Poetics. New York: Palgrave Macmillan, 2009.

HIRASHIMA, Cézar Katsumi. O Haikai nas Artes Visuais: Tradução Intersemiótica. 2007. 192 fls. Dissertação (Mestrado em Artes) - Universidade de São Paulo, São Paulo, 2007.

HOOKWAY, Christopher. Truth Rationality, and Pragmatism: Themes from Peirce. Oxford: Oxford University Press, 2002.

HULSWITT, Menno. Semeiotic and the Cement of the Universe: A Peircean Process Approach to Causation. Transactions of the Charles S. Peirce Society: A Quarterly Journal in American Philosophy, v. XXXVII, n. 3, p. 339-363, 2001.
KANEOYA, Iochihiko. O Haikai, Haicai ou Haiku. Disponível em: <http://www.nipocultura.com.br/?p=242>. Acesso em: 10 fev. 2018.

KERKHAM, Eleanor. Matsuo Bashô's Poetic Spaces: Exploring Haikai Intersections. New York: Palgrave Macmillan, 2006.

LEMINSKI, Paulo. Ensaios e anseios crípticos. São Paulo: Editora da Unicamp, 2011.

LEMINSKI, Paulo. Bashô. São Paulo: Brasiliense, 1983.

LEITE, Elizabeth Rocha. Leminski: O Poeta da Diferença. São Paulo: Ed. USP, 2012.

MARTY, Robert. C.S. Peirce's Phaneroscopy and Semiotics. Semiotica, v. 1/4, n. 41, p. 169-181, 1982.

NAKAEMA, Olivia Yumi. Haicais de Paulo Leminski: Uma Abordagem Semiótica. Cad. Pesq. Grad. Letras USP, v. 1, n. 1, p. 252-260, 2011.

PAZ, Octavio. Signos em rotação. São Paulo: Perspectiva, 1976.

PEIRCE, Charles S. The Essential Peirce. Selected Philosophical Writings. (EP seguido pelo número do volume e página). EP 1 edited by HOUSER, Nathan; KLOESEL, Christian; EP 2 edited by the Peirce Edition Project. Bloomington and Indianapolis: Indiana University Press, 1992, 1998.

PEIRCE, Charles S. The Collected Papers of Charles Sanders Peirce. (CP seguido pelo número do volume e parágrafo). Electronic edition reproducing Vols. I-VI [HARTSHORNE, Charles; WEISS, Paul (Eds.). Cambridge: Harvard University Press, 1931-1935]; Vols. VII-VIII [BURKS, A. W. (Ed.). Same publisher, 1958]. Charlottesville: Intelex Corporation, 19311935.

PEIRCE, Charles S. Annotated Catalogue the Papers of Charles Sanders Peirce. (MS seguido pelo número do manuscrito). ROBIN, Richard.S. (Ed.). Massachusetts: The University of Massachusetts Press, 1967.

PEIRCE, Charles S. New Elements of Mathematics by Charles Sanders Peirce. (NEM seguido pelo número da página). EISELE, Carolyn (Ed.). The Hague: Mouton, 1976.

PICARDI, Eva. La chimica dei concetti. Lingua e Stile, v. 25, n. 3, p. 363-381, 1990.

QUEIROZ, João. Semiose segundo C. S. Peirce. São Paulo: Educ/Fapesp, 2004.

QUEIROZ, João. Tradução criativa, diagrama e cálculo icônico. Alea: Estudos Neolatinos, v. 12, p.322-332, 2010.

QUEIROZ, João; EL-HANI, Charbel. Towards a Multi-level Approach to the Emergence of Meaning in Living Systems. Acta Biotheoretica, n. 54, p. 179-206, 2006.

RIBEIRO, Thales de Medeiros et al. (Des)construindo Haicais: o entre-lugar na poesia de Mário Quintana e Paulo Leminski. Travessias, v. 5, p. 213-235, 2011.

ROSENSOHN, William. The Phenomenology of C.S. Peirce: From the Doctrine of Categories to Phaneroscopy. Amsterdam: B. R. Gruner, 1974.

SAVAN, David. On the origins of Peirce's phenomenology. In: WIENER, Philip; YOUNG, Frederic (Orgs.). Studies in the Philosophy of Charles Sanders Peirce. Harvard: Harvard University Press, 1952. 
SPIEGELBERG, Herbert. The Context of the Phenomenological Movement. The Hague: Martinus Nijhoff, 1981.

SOUSA, Tatiane. Haicais de Bashô: O oriente traduzido no ocidente. 2007. 136 fls. Dissertação (Mestrado em Linguística Aplicada) - Universidade Estadual do Ceará, Fortaleza, 2007.

STJERNFELT, Frederik. On Operational and Optimal Iconicity in Peirce's Diagrammatology. Semiotica, n. 186, p. 395-419, 2011.
TURSMAN, Richard. Peirce's Theory of Scientific Discovery: a System of Logic Conceived as Semiotics. Indiana: Indiana University Press, 1987.

Recebido: 08/10/2017

Aprovado: 04/02/2018

\section{Contato:}

Ana Fernandes < analuizadagama@gmail>

João Queiroz<Queirozj@gmail.com> 